\title{
TECHNOLOGICAL CULTURE REPERCUSSIONS AND ITS EFFECT ON THE FUTURE OF ARCHITECTURE
}

\section{Samira Jamal Jameel}

Participating Lecturer, Dept. of Architecture, Faculty of Engineering, Sana'a University)

\section{(Recieved October 9, 2007 Accepted November 28, 2007)}

Information and automation are considered the most important technologic achievements that form the future lineaments. Also, the breakthrough increating the materials directed forward high performance competence and the using of modern techniques in architecture have changed number of the prevailing concepts in the technical sciences. The future challenges makes it compulsory to review all what is surrounding the architecture process as of theoretical principles and practical procedures on the light of modern concepts of architecture requirements from scientific and technological point of view having impact on the methods of architectural designs. The problem is to be in the challenges facing the architect in finding new architectural language that invest and accompany the increasing progress in the modern techniques; which requires updating the architectural concepts, requirements and tools as well as developing the architect ability to absorb and direct the available data, alternatives and performance styles by making change in the core of teaching and practicing methods of design. The research aims to observe the technological culture Repercussions and its most important features on the activities of architecture, and the possible stability for the majority of these repercussions and their relation in the future of architecture through the research procedures that include the following axis:

- The future as prospective and intellectual approach: It deals with the concept and types of future studies and the role of forecast in the planned change.

- Technology as technical and social phenomenon: This deals with the concept of - technology and technicality and the social insight of technology.

- Patterns of the contemporary technical change: Deals with the most important technological achievements forms the lineaments of the contemporary, future and technical change such as:

- Information technology, digital design, industrial automation norms and new materials technology.

- Lineaments of technological culture: deals with information culture and knowledge industry, technical globalization and its repercussions on the social and culture environment, architecture as after modernity and conformity forms with technology age. 
- The impact of technology on the development of modern attitudes in the design: deals with the forms of the technological impact forms on the modern attitudes of construction and internal design.

- The future of architecture education, development of creative notion and the most important characteristics of creative education.

\section{انعكاسات الثقافة التكنولوجية وتأثيرها على الاتجاهات المستقبلية في التصميم المعماري}

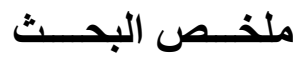

تعتبر المعلوماتية و الاتوماتية من أهم المنجزات التكنولوجية التي تتكل ملامسح المستقبل ، كمـا أن التقدم

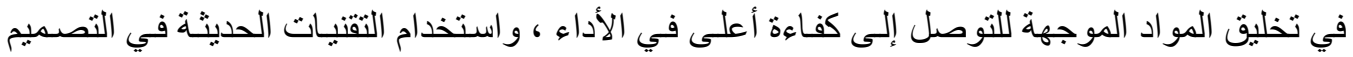
المعماري قد غير العديد من المفاهيم السائدة في العلوم التقنية.

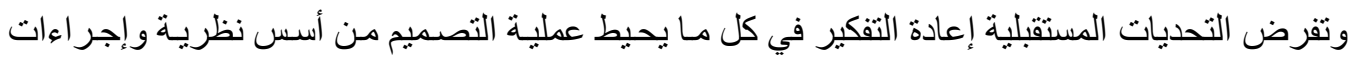

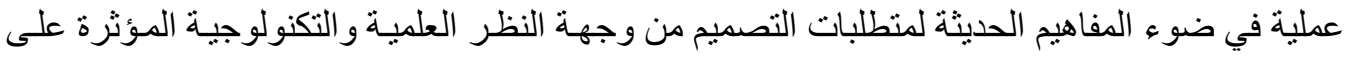

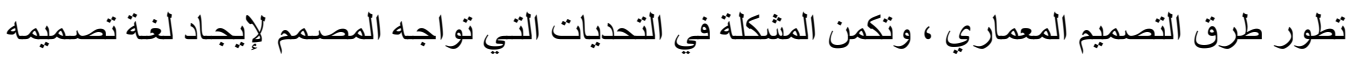

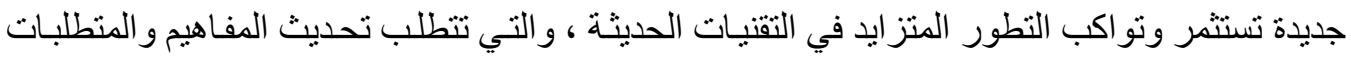

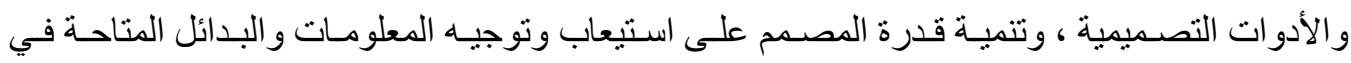
الخامات وأساليب التنفيذ من خلال إحداث تغيير في جو هر أساليب تعليم وممارسة التهاب التصميح.

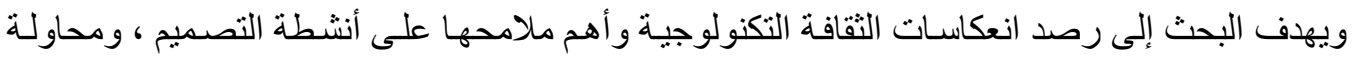

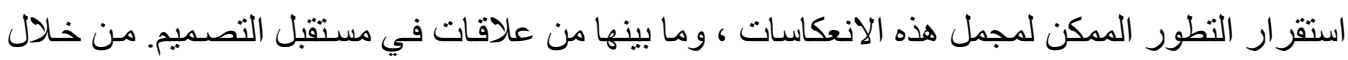
إجر اءات البحث والتي تنتاول المحاور التالية:-

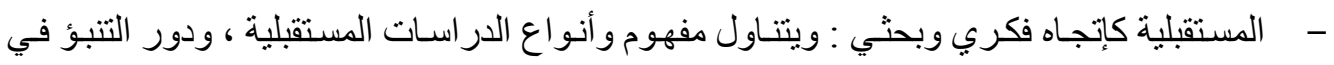
التغيير المخطط. - - التكنولوجيـا كظـاهرة تقنيـة و اجتماعيـة : ويتتـاول مفهوم التكنولوجيـا و التقنيـة و البعـد الاجتمـاعي اللتكنولوجيا.

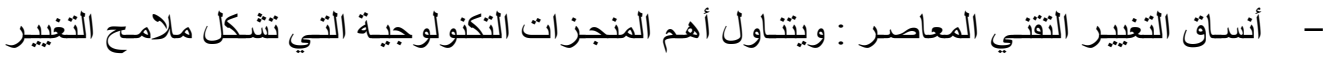

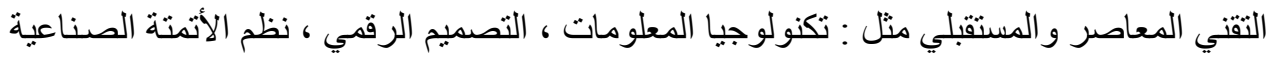
، تكنولوجيا المواد الجديدة.

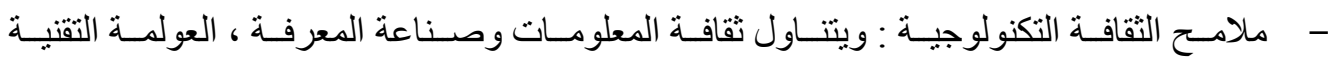

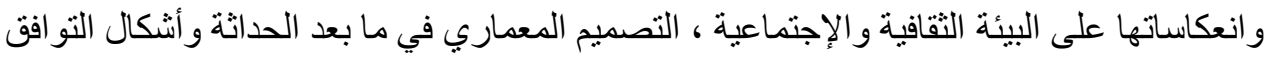
مع عصر التقنيات. - - أثر التكنولوجيا على تطور الاتجاهات الحديثة في التصميم : ويتتاول أثنكال التنأثير التكنولوجي في

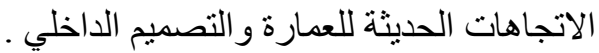
- مستقبل تعليم التصميم المعماري وتتمية الفكر الإبداعي و التقني و أهم خصائص التعليم الإبداعي. 
1- المقــدمــة :

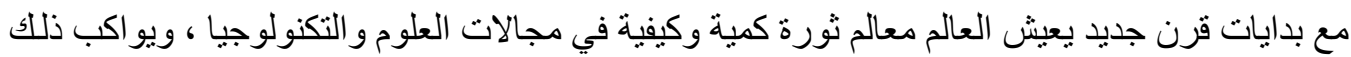

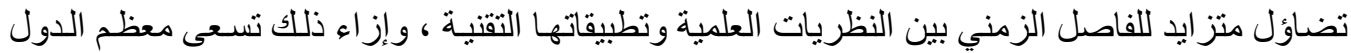

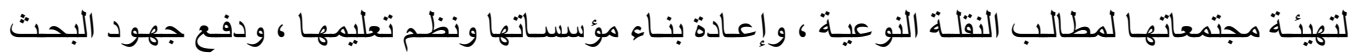
و التطوير والتحديث ، فكيفما يكون الثكل المستقبلي للمجتمع فإنه من المؤكد أن إسهام التكنولوجيا لونهاء سيكون

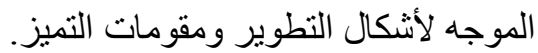

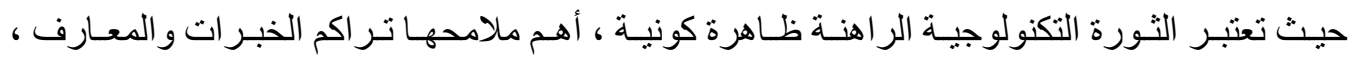

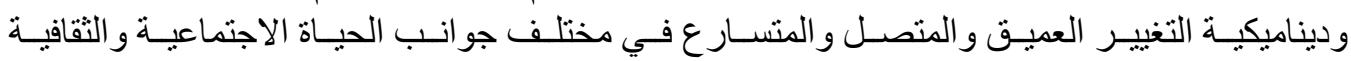

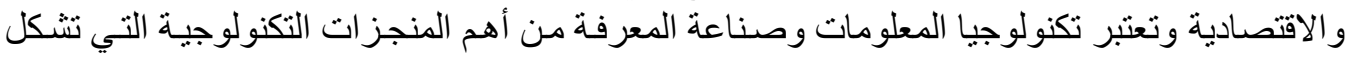

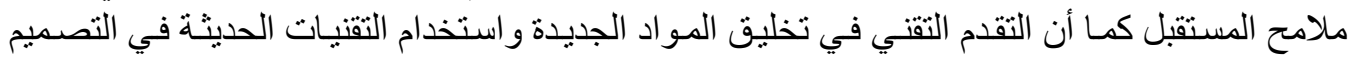
و التصنيع قد غير العديد من المفاهيم السائدة في العلوم التطبيقية والفنون الإنتاجية.

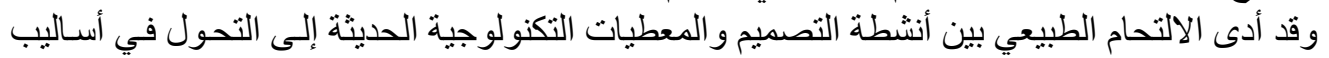

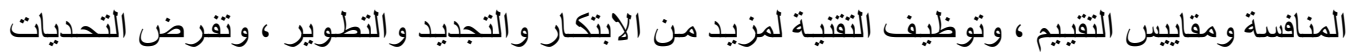

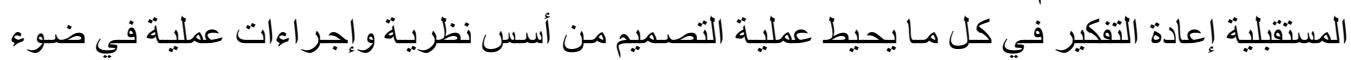

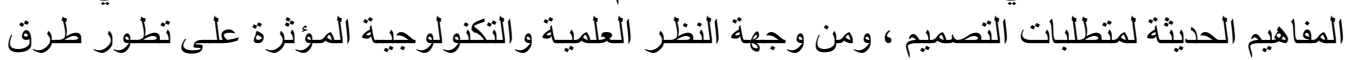
التصميم و الإنتاج.

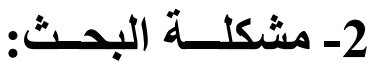

تكمن المشكلة في إيجاد لغة تصميمه جديدة تستثمر وتو اكب التطور المتز ايد في التقنيات الحديثة ، و التي تتطلب تحديث المفـاهيم و الأدوات التصميمية ، وتتميـة قدرة المصمم على استيعاب وتوجيـه المعلومـات

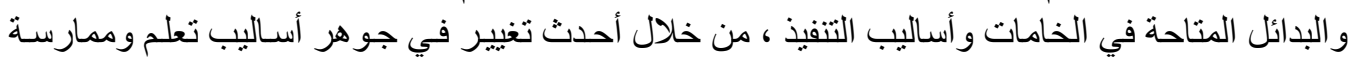
التصميم انطلاقا من الفروض التئن التالية: أـ إن مستقبل التصميم يعتمد على قياس المتغير ات التكنولوجية ولتوفية أثر هـا على التكوين الثقافي و الاجتمـاعي و الاقتصادي للمجتمع. بـ ـ إن تتمية مهار ات التصميم تحقق مصدر متجدد للتميز و النمو ، حيث يصبح الإبـداع والابتكار سمة التطور و النجاح و الاستمرار. ج- إن المعدل الفائق لحدوث التغيير يمثل عبئًا على مستقبل تعليم التصميم في التكيف مـع هذا المعدل ، التهي

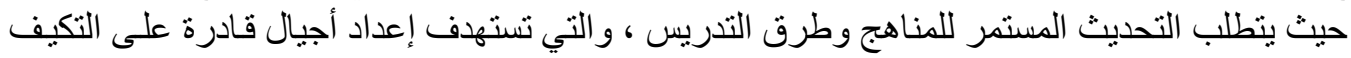
والإبداع و المشاركة. مان.

د- إن الإستجابة للتطور التقني أمر حتمي - فالمستقبل لمن يمتلك المعرفة والتهب التقنية. هـ- إن التحديث ليس أحادى الاتجاه - بمعنى أنه ليس في الأدوات فقط ولكنه في الفكر و الأسلوب.

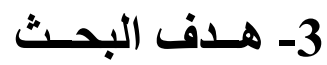

يهذف البحث إلى رصد انعكاسـات الثقافة التكنولوجية وأهم ملامحها على أنشطة التصميم ، ومحاولة استقر اء التطور الممكن لمجمل هذه الانعكاسـات ومـا بينها مـن علاقـات في مستقبل عمليـة التصـميم كممارسة وتعلم ، من خلال در اسة مدخلات تطور الفكر والأسلوب والاتجاهات التصميمية الحديثة. 


\section{4- خطوات البحث تثمل دراسة المحاور التالية:}

1/4 - المستقبلية كاتجاه فكري وبحثي. 2/4- التكنولوجيا كظاهرة تقنية واجتماعية. 1/4 النية.

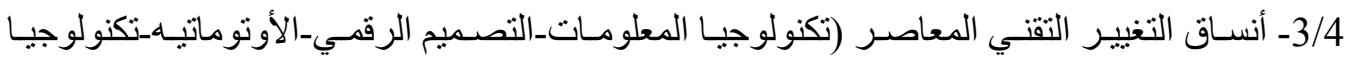

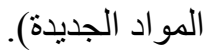

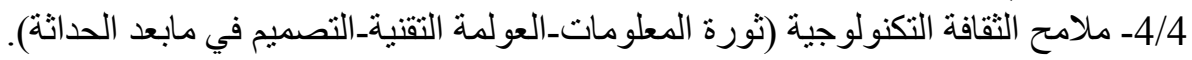

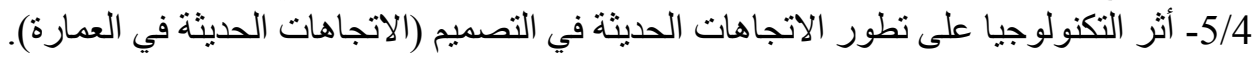

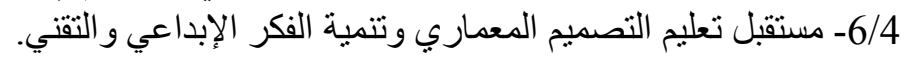

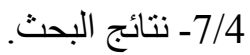

\section{1-4/ المستقبلية كاتجاه فكري وبحثي}

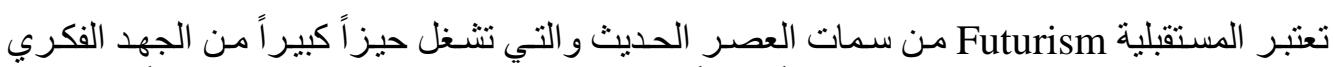
الإنساني ، حيث يمتلك الفكر المستقبلي بعداً فلسفياً بمكنه من تقديم رؤية أكثر شمولية واتساعاً.

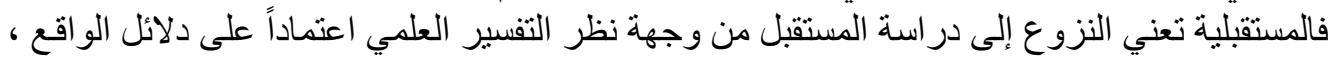

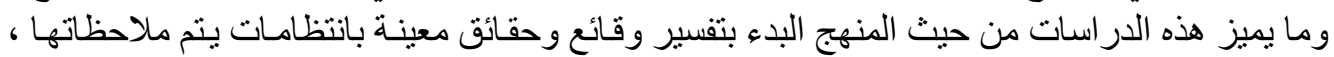

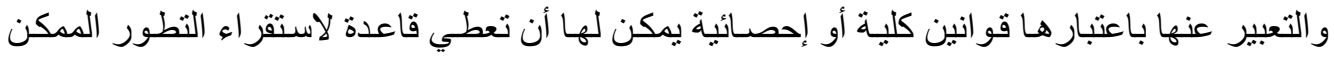

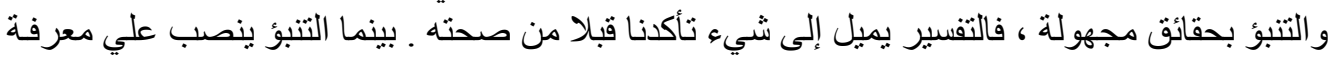

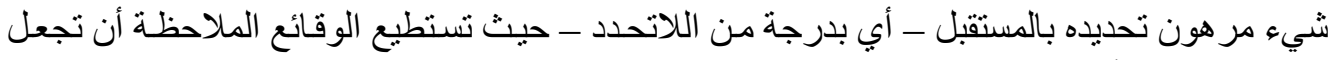

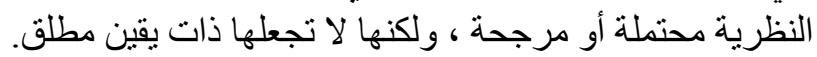

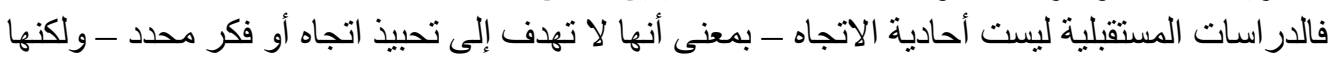

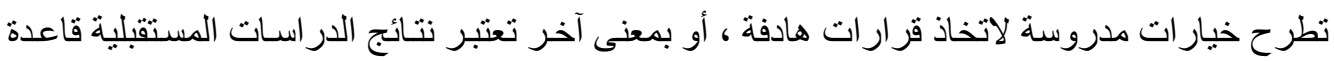

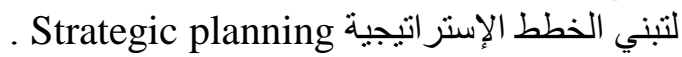

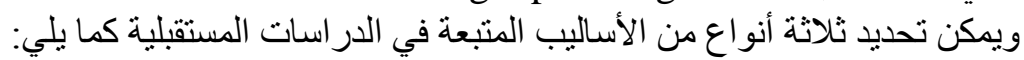

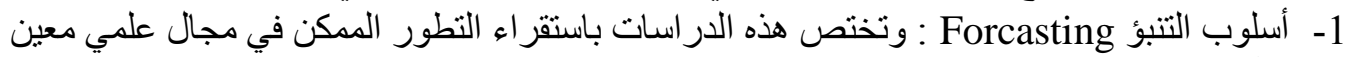

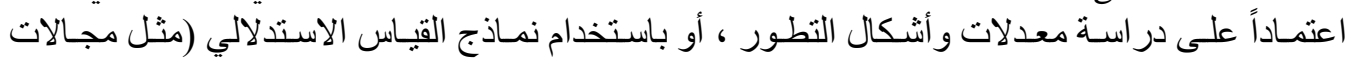

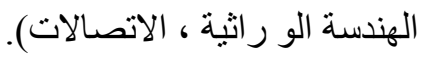

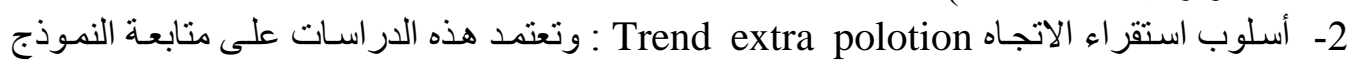

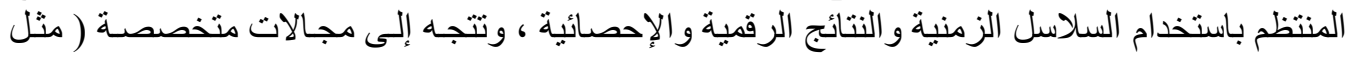

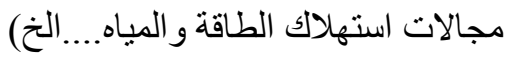

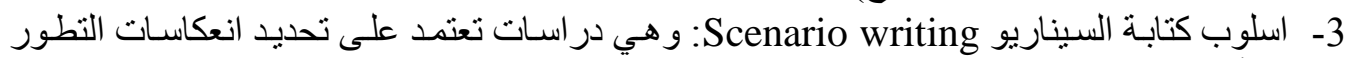

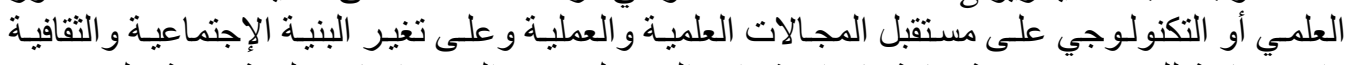

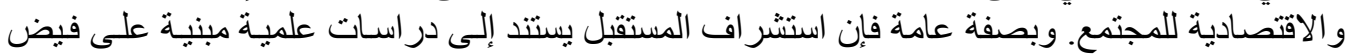

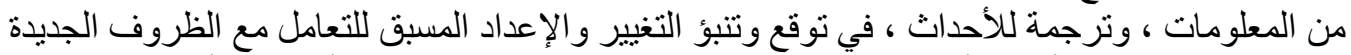

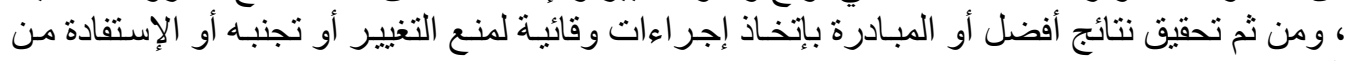




\section{2/4- التكنولوجيا كظاهرة تقنية واجتماعية:}

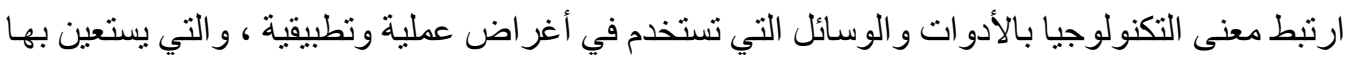
الإنسان إكمال قدر اته العملية ، وتلبية حاجاته الإجتماعية.

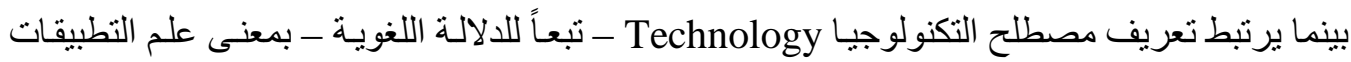

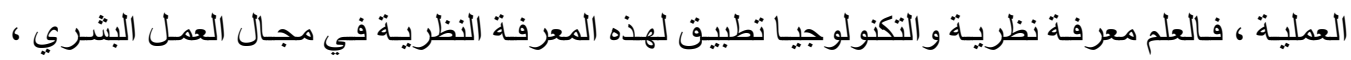

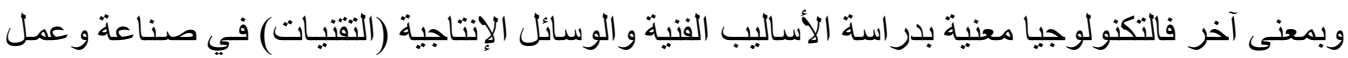
الأشياء و التقنية ذاتها تجسيد وتجميع للمعارف و الخبر ات و المهار ات البشرية في شكل وسائل وفنون

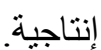

ويمكن تصنيف التقنية من هذا المفهوم إلى عنصرين منكاملين هما:-

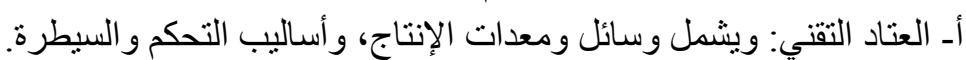

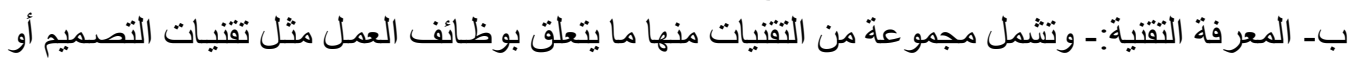

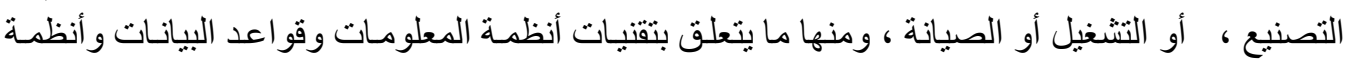

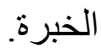

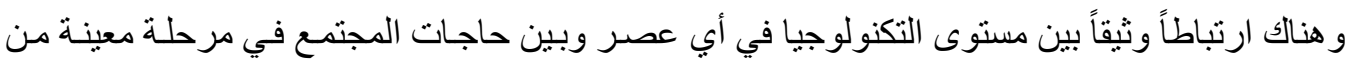

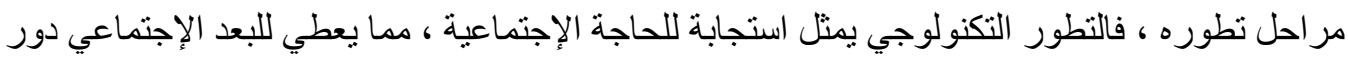

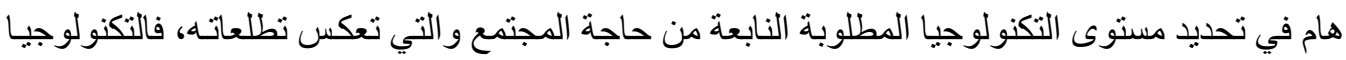

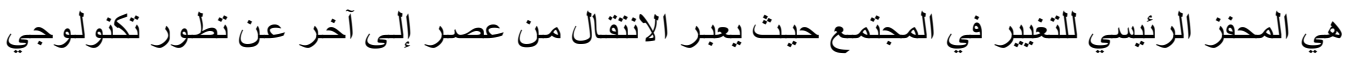
مؤثر.

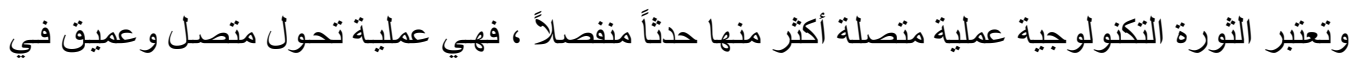

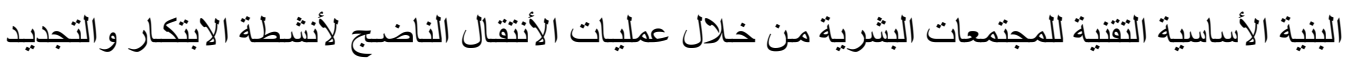
و والتطوير.

\section{3/4 انساق التغيير التقي المعاصر}

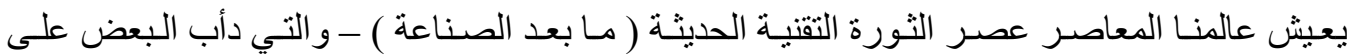

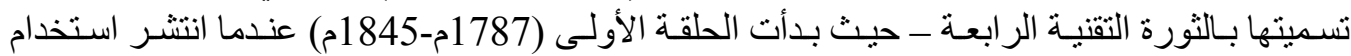

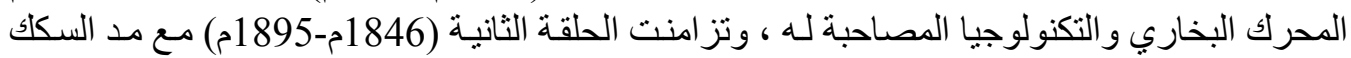

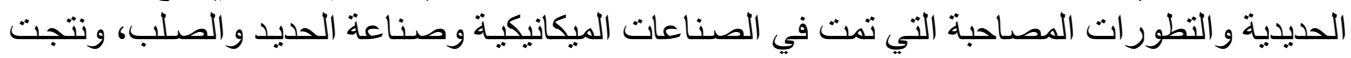

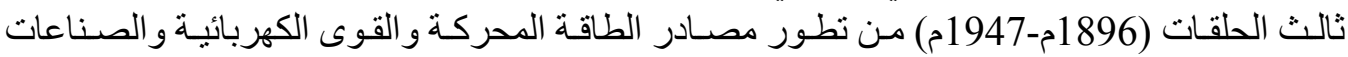

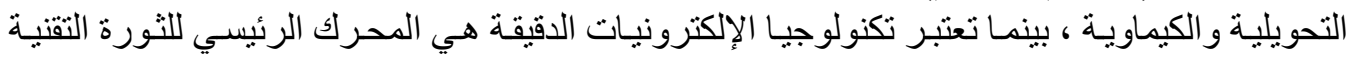

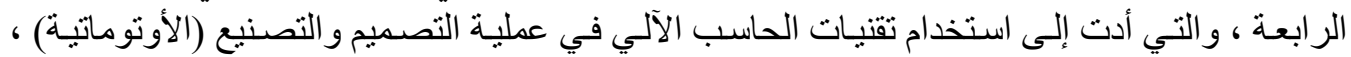

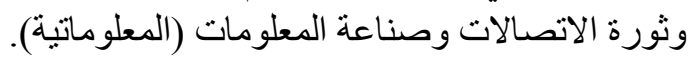

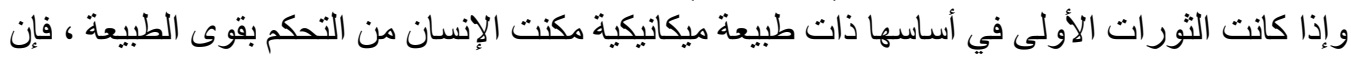

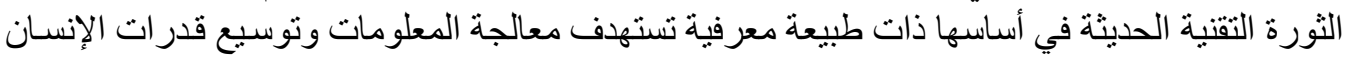

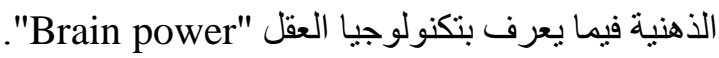
و هنالك بعض السمات التي تتميز بها الثناعة التورة التقنية المعاصرة أهمها مايلي:-

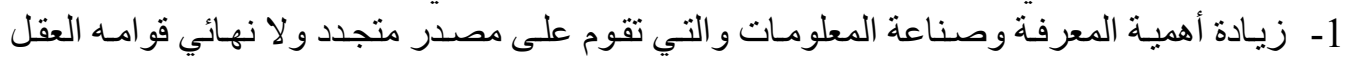
البشري. 


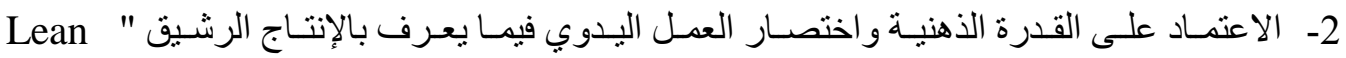
"production فبعد أن كانت الثور ات الأولى تعتمد على الجهد البشري كمدخل أساسي في أنظمـة الإنتاج ، أصبحت

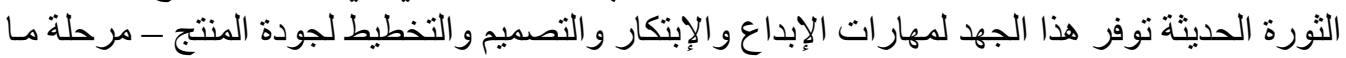

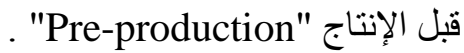
3- من أهم الآثار الاقتصادية للثورة التقنية إعادة تنظيم الروابط الاقتصادية و التجارية العالمية مثل: قيام

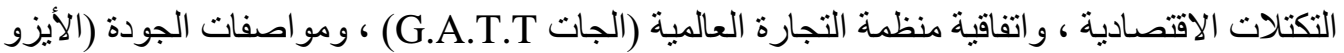

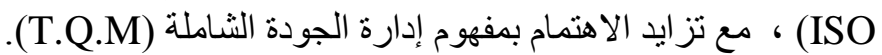

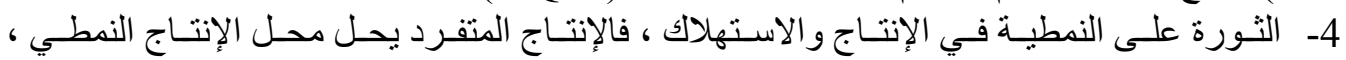
و الاستهلاك المتميز يتحول إلى استهلاك جماهيري. 5- كثفت الثورة التقنية المعاصرة عن تقسيم دولي جديد للعمل ، يعطي الدول التي تمتلك التقنية الهيمنة

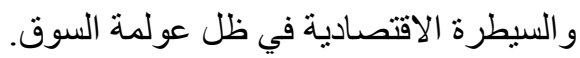

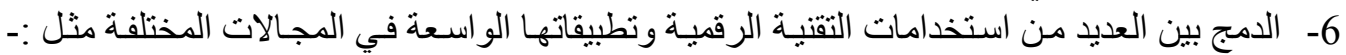

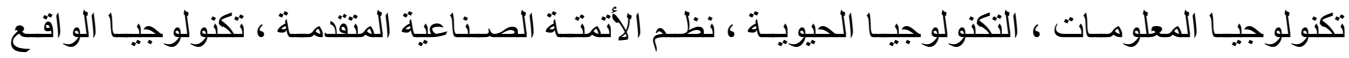
الافتر اضي و العو الم المصطنعة.

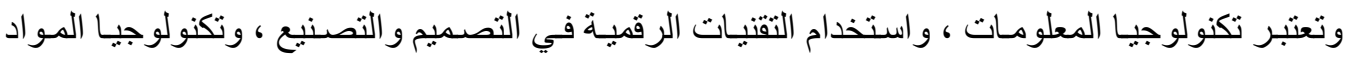

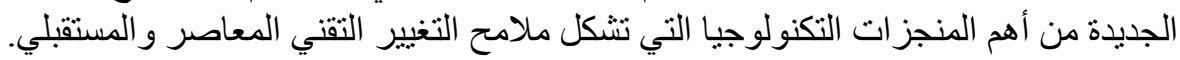

\section{1/3/4- تكنولوجيا المعلومات:}

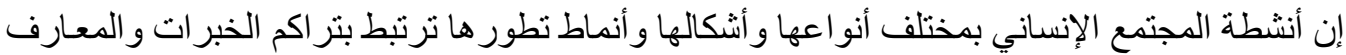

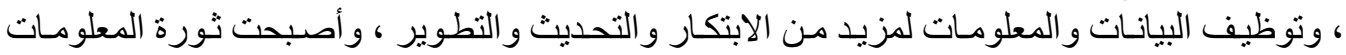
السمة الرئيسية التي تشكل معالم الثورة التقنية الحديثة.

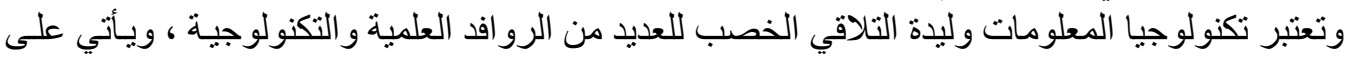

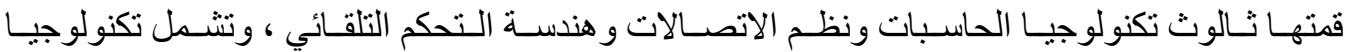

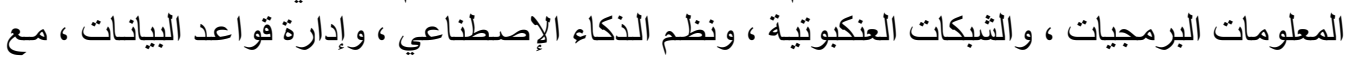

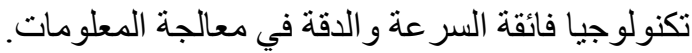

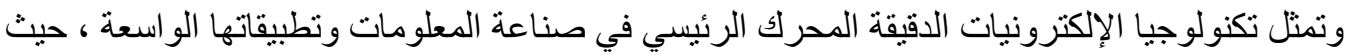

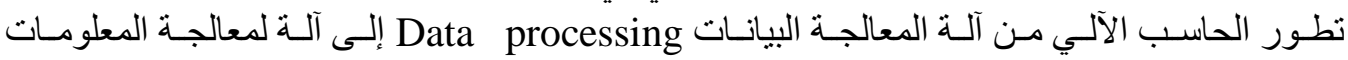

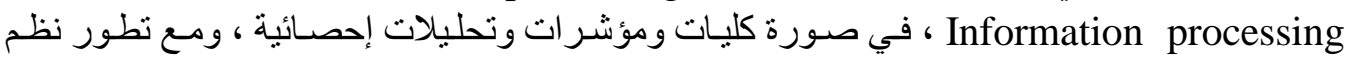

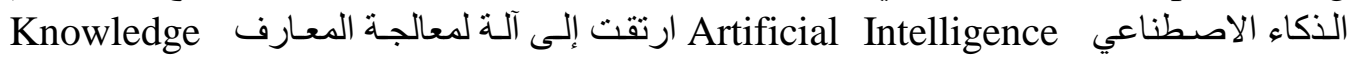
والحكمة ، processing

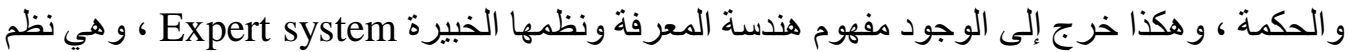

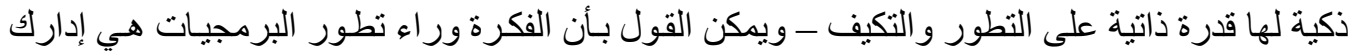

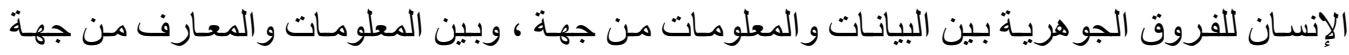



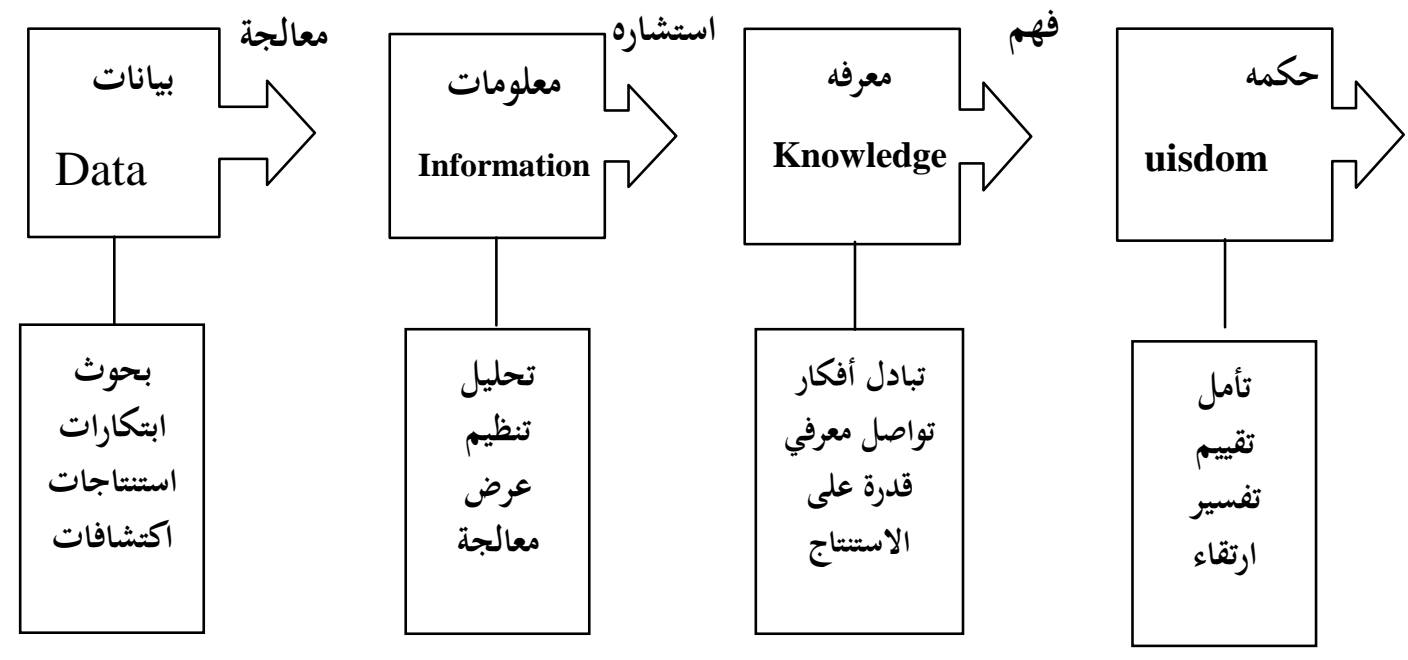

شكل (2) نظم صناعة المعلومات

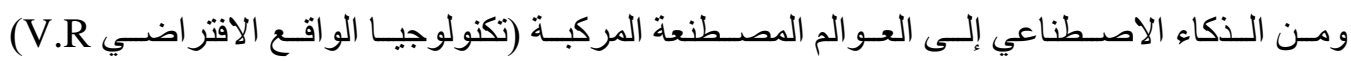
Synthesized World, Virtual Reality

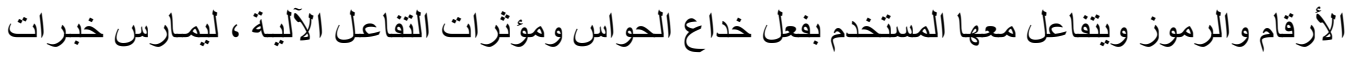

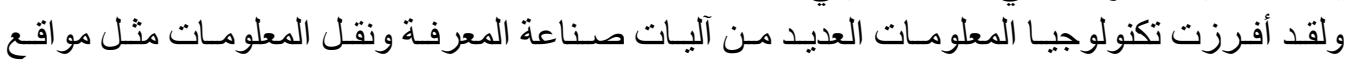

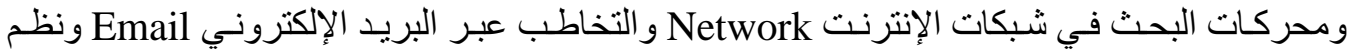

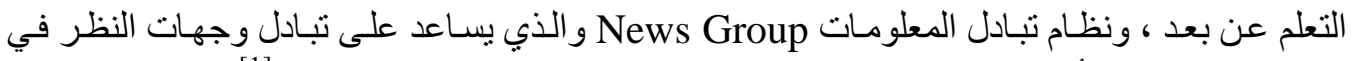

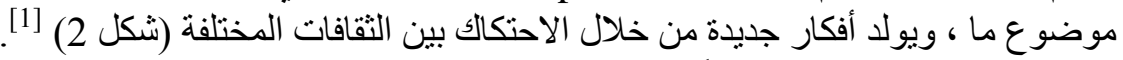

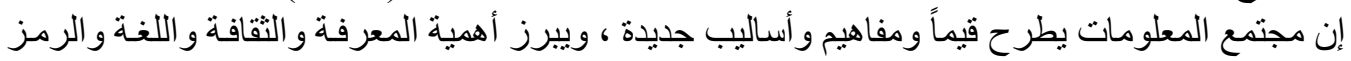

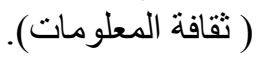

\section{2/3/4 تكنولوجيا التصميم الرقمي: تكني:}

تعتمد تكنولوجيا التصميم الرقمي Digital design على الاستفادة بتقنيات الحاسب الآلي و البرمجيات

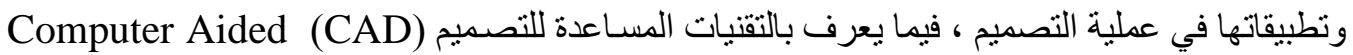
Design

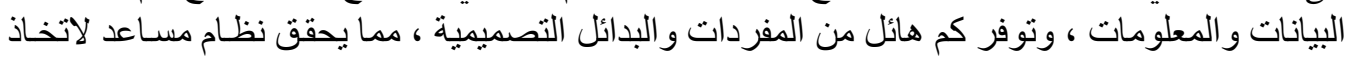

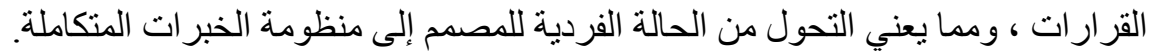
و تتندرج مستويات تطبيقات التصميم الرقمي في مر احل التصميم كمايلي:-

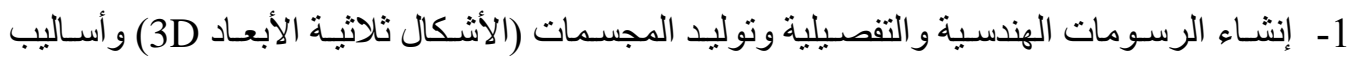
إخر اج وعرضها ، من خلال أفكار مقتنة تتو افق مـع إمكانيات الحاسب الآلي فيما يسمى بعمل الأبعاد الأشكال

[1] Richard Warman,"Information Anxietty", USA, 1998. 


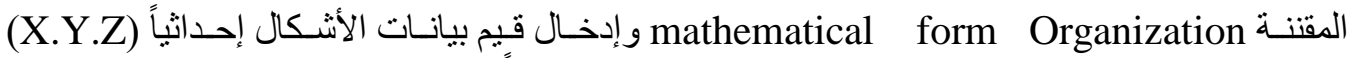

للحصول على تصور رقمي للعمل التصميمي و الاستفادة به إنتاجياً.

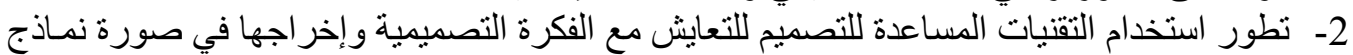

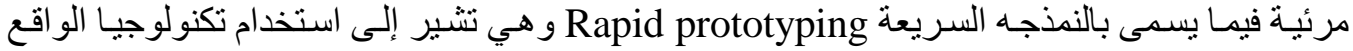

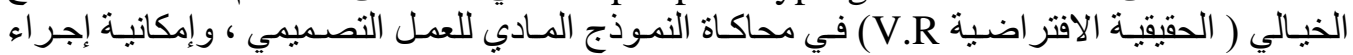

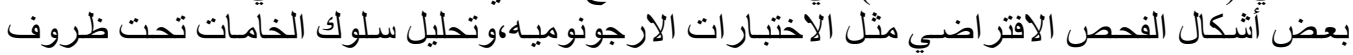

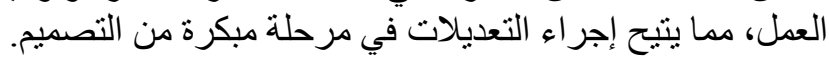

\section{3/3/4 تكنولوجيا المواد الجديدة}

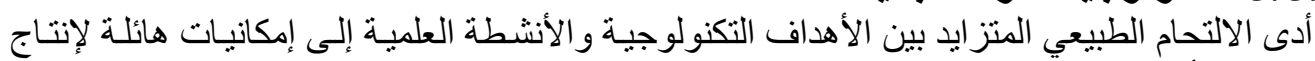

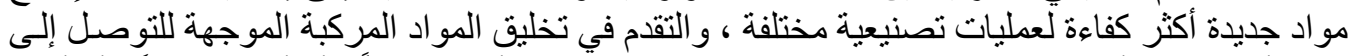

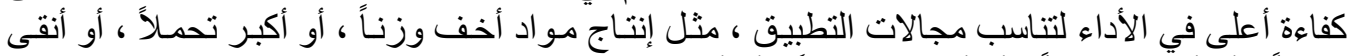

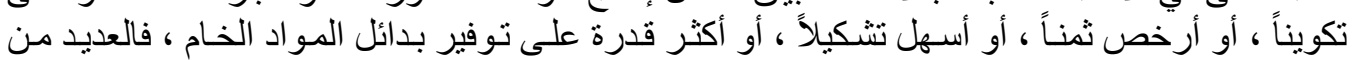

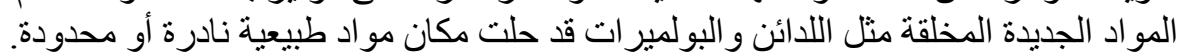

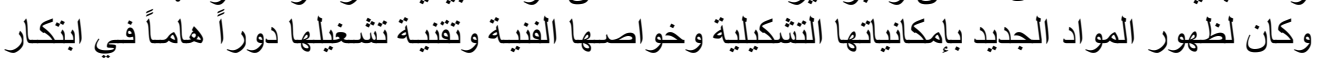

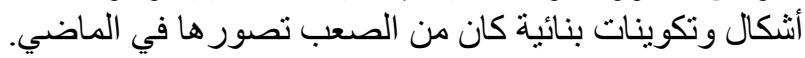

\section{4/4 - 4لامج الثقافة التكنولوجية:}

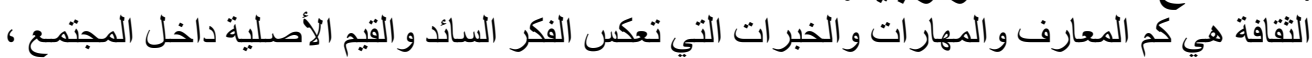

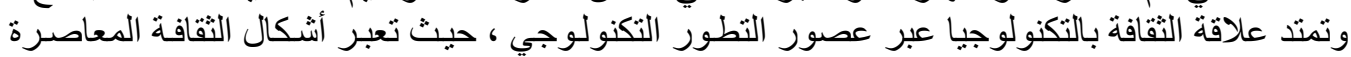

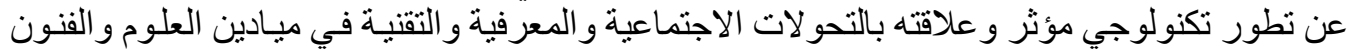

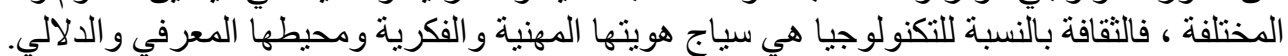

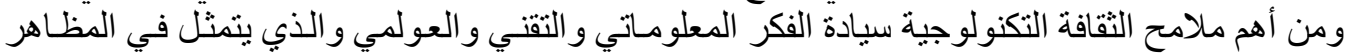

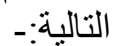

\section{1/4/4 ثقافة المعلومات}

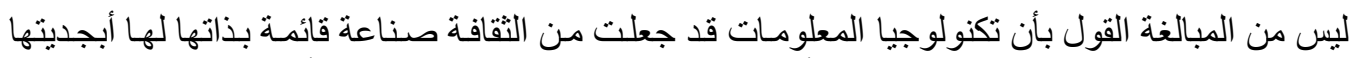

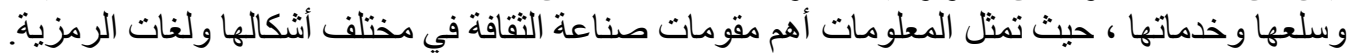

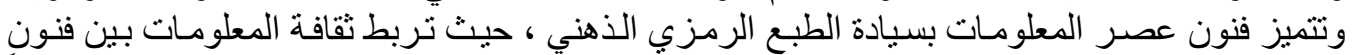

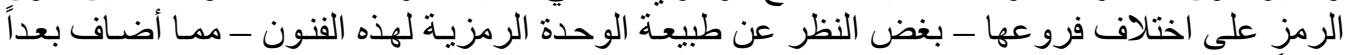
جديداً لوظيفة الفن صلة وثيقة بتنمية الفكر ذاتهـ.

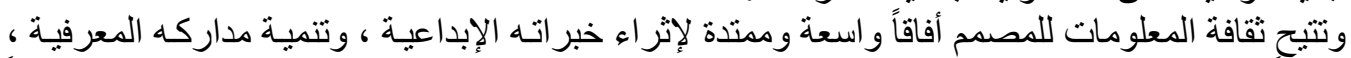

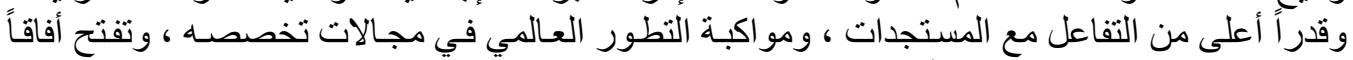
جديدة للتعبير عن نفسه وترويج ألفاعل أعماله. كما حولت ثقافة المعلومات المتلقي من مستقبل سلبي إلى مشئ مشارك إيجابي باستطاعنه أن ينفذ إلى أعمال وتفاصيل العمل الفني ، مما يحقق نظام خبرات متكاملة في العملية التصميمية.

\section{2/4/4 - العولمة التقتية:}

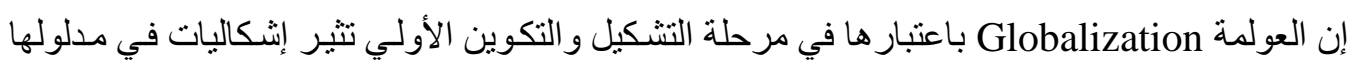

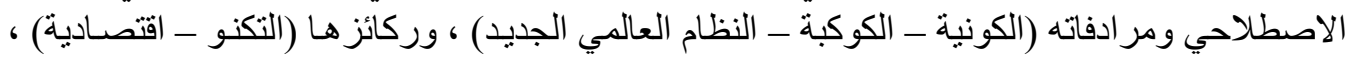

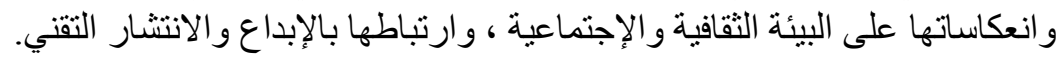


مما ينعكس على تباين المو اقف حول ظاهرة العولمة ، فالمؤيدون يعتبرون العولمة ظاهرة إنسانية إيجابية

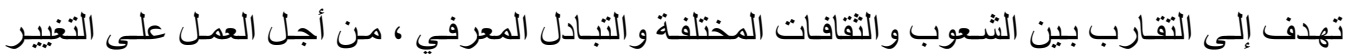

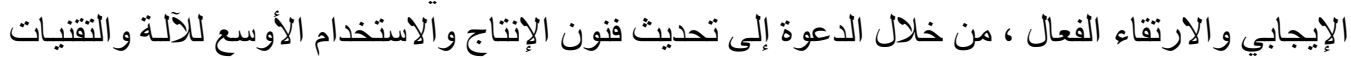

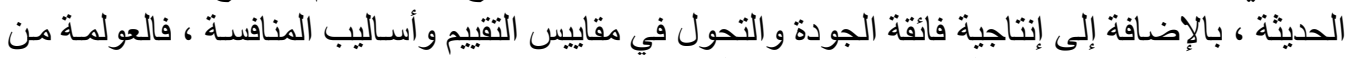

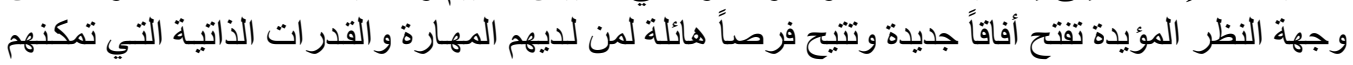
من الحركة و الازدهار في الأسواق العالمية.

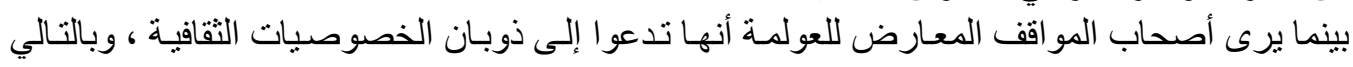

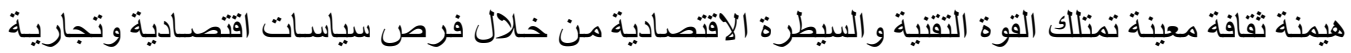

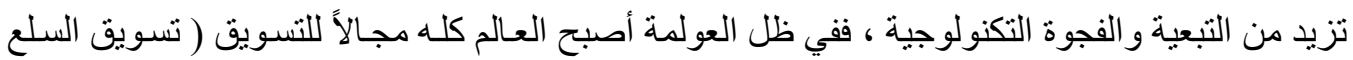

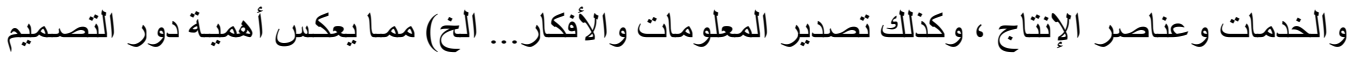

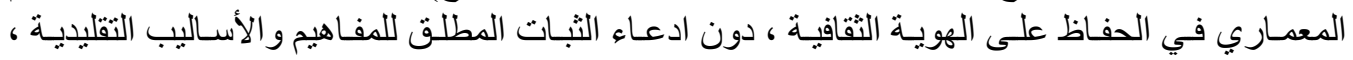

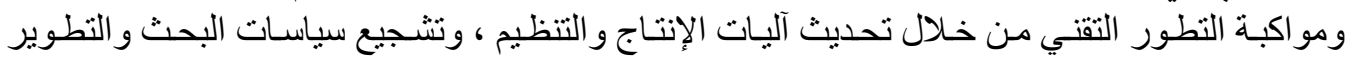
والتغيير المخطط ، وتوفير المناخ الإبداعي.

\section{3/4/4- التصميم في ما بعد الحداثة:}

كان لظهور الحركة الصناعية الأثر الواضح في التحول من النموذج العقائدي ـ الذي كان مسيطر اً في

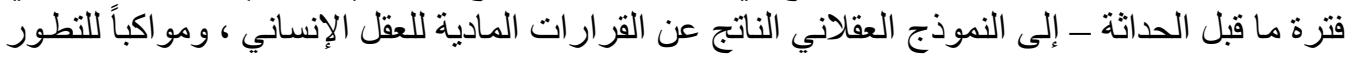
الطبيعي للعلوم و التكنولوجيا.

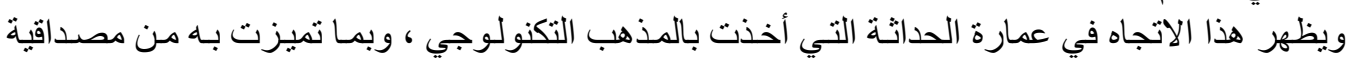

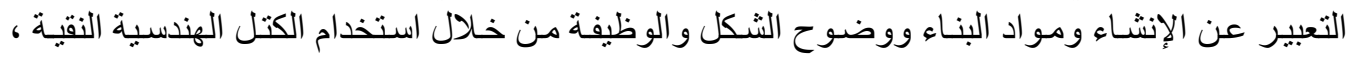

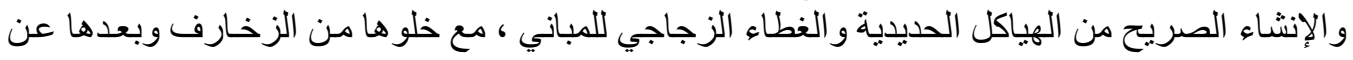
هوية التشخيص. وتمثل الباوهاوس Bauhaus أحد التيار ات الفنية المؤثرة في العمارة والتصميم في عصر الحداثة والتي التي

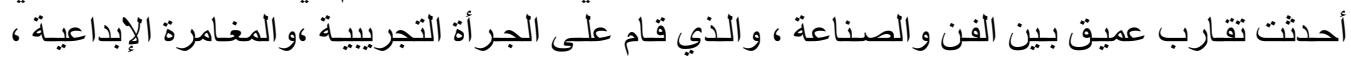

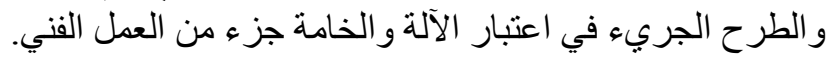

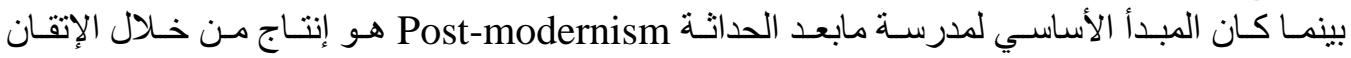

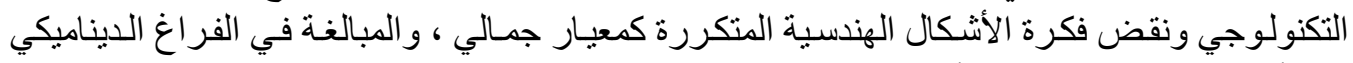

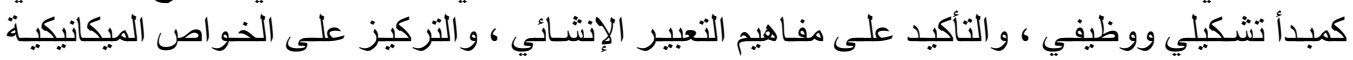

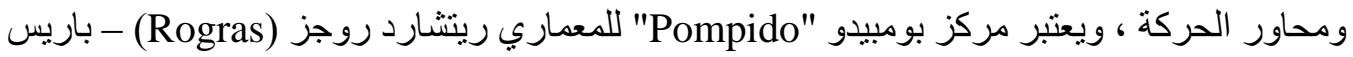

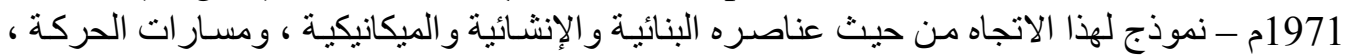

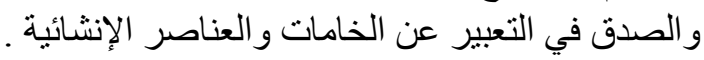
وظهر مفهوم ما بعد الحداثة كاتجاه للتحرر من قيود الصر امة في الثكل و الفكر و الاتجـاه نحو ذاتيـة أكثر

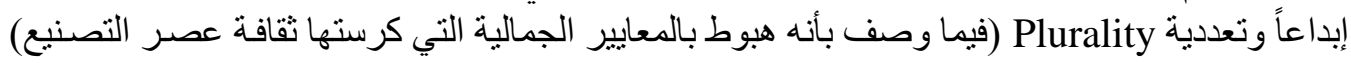

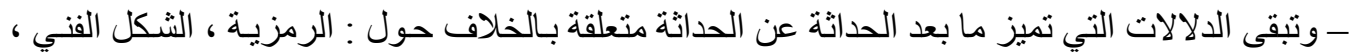

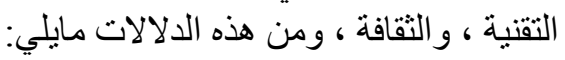

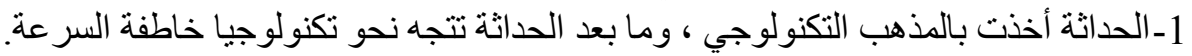

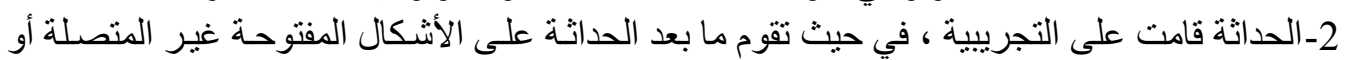

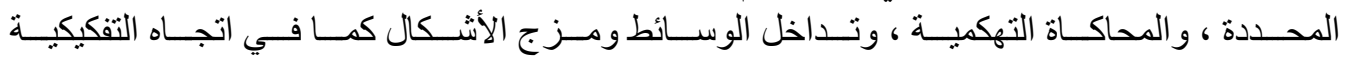


3-قامت الحداثة على التناقضية ، بينما تدعو ما بعد الحداثة إلى الثقافات المتقابلة ، وقبول عدم الترابط

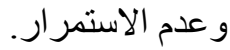
و اتجهت عمارة ما بعد الحداثة إلى التحرر من صمت الأثكال الخالصة ومن صخب الإنشاء الملفت للنظر حرية أكثر

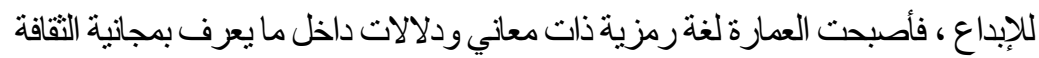

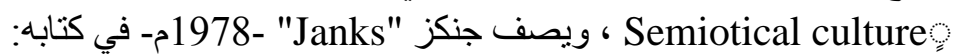

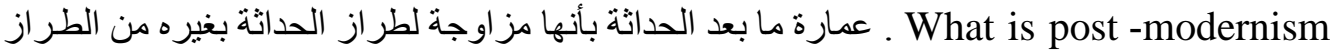

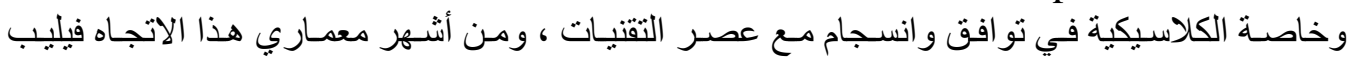
جونسون "Johnson" ومايكل جريفز "Graves" وروبرت فنتورى "Venturi"

5/4- أثر التكنولوجيا على تطور الاتجاهات الحديثة في التصميم:

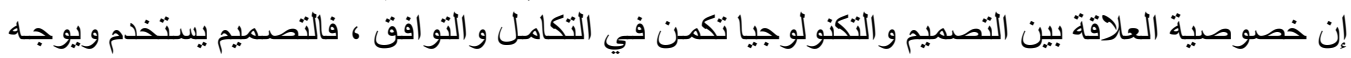

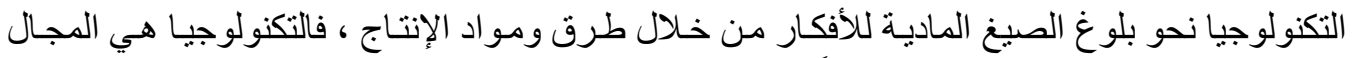

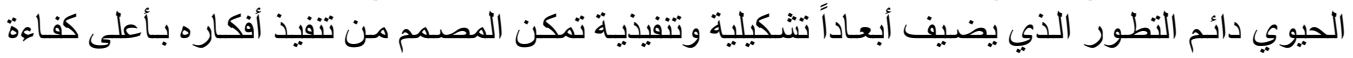

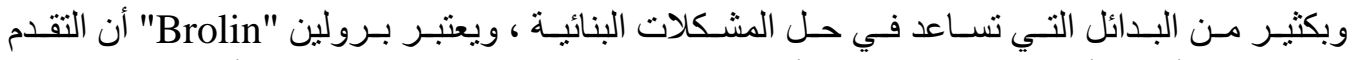

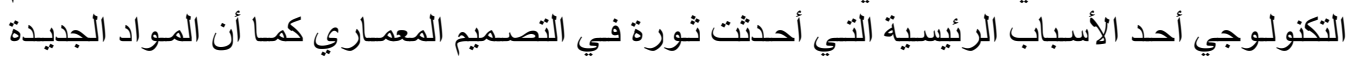

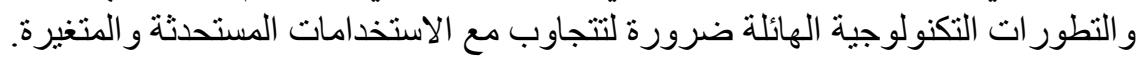

\section{1/5/4 الاتجاهات الحديثة للعمارة:}

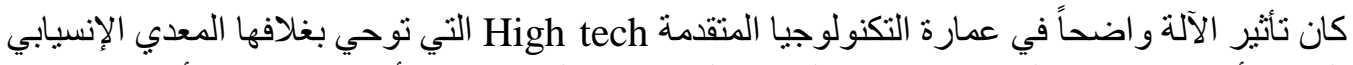

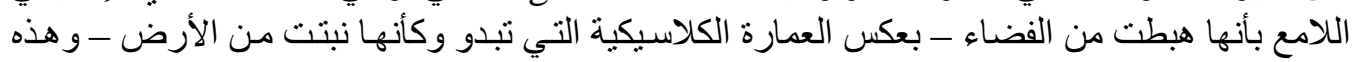

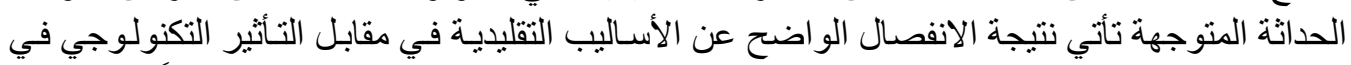

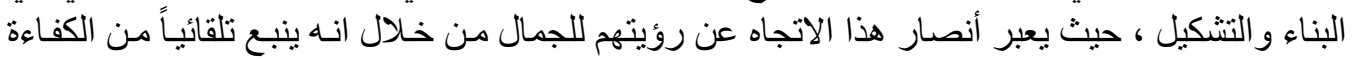

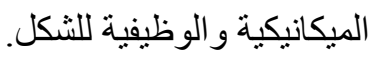

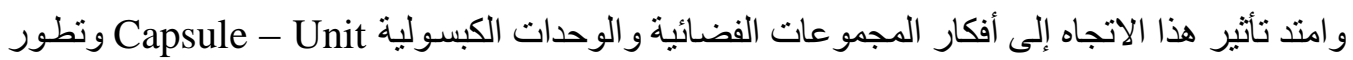

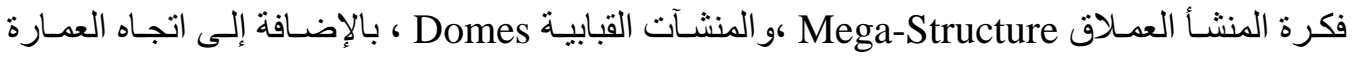

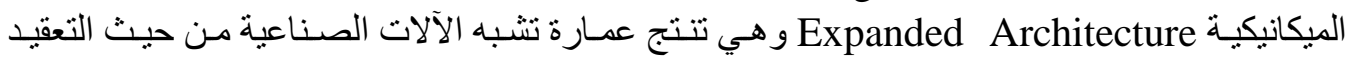

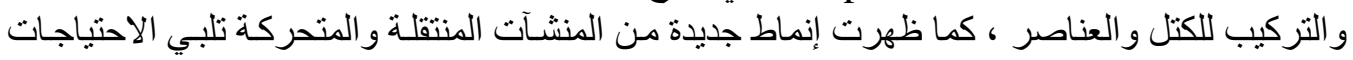

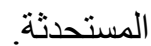

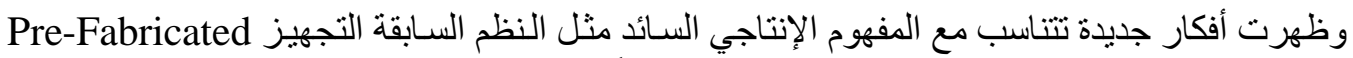

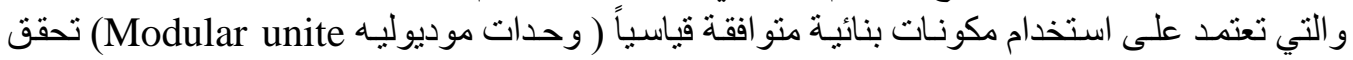

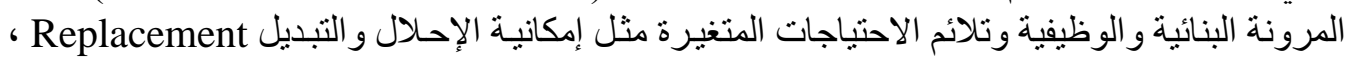

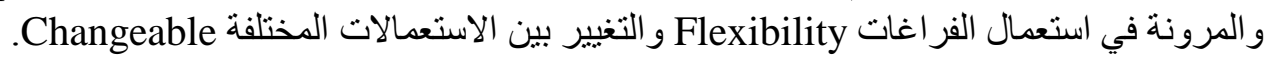

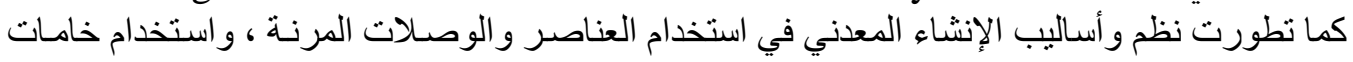

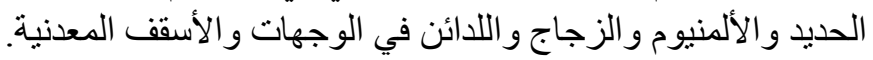

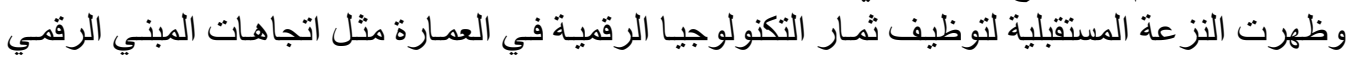
Digital building

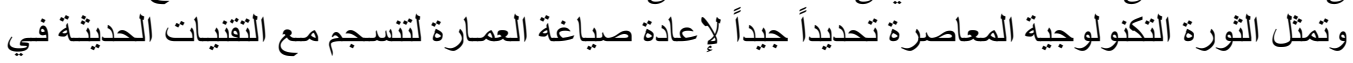

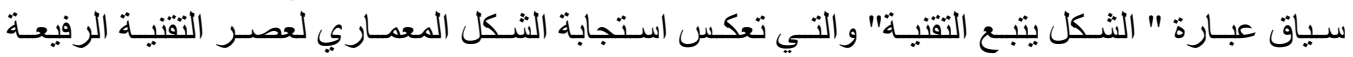

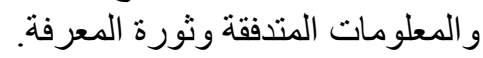


6/4- مستقبل تعليم التصميم وتنمية الفكر الإبداعي والتقي.

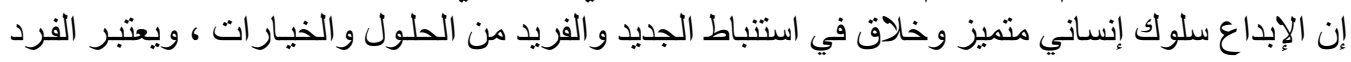

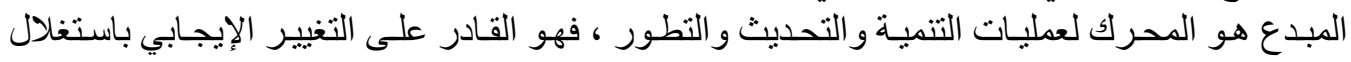

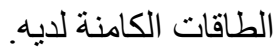
كما يرتبط الإبداع بالمناخ الثقافي العام للمجتمع ، و الظروف الموضو عية لاستنباته ونموه.

\section{1/6/4- أهم أسس النهوض الإبداعي:-}

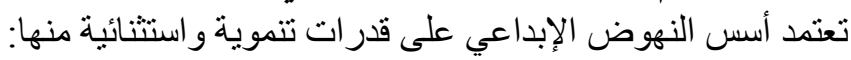

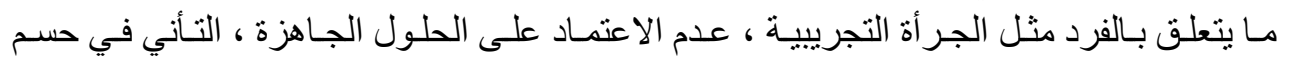

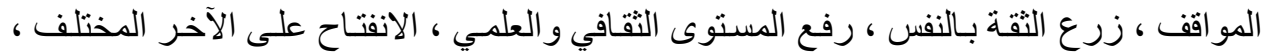
مواجهة التحديات ، نقد النتائج و النظريات.

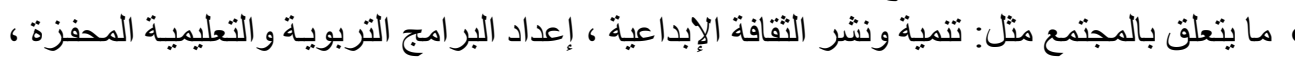

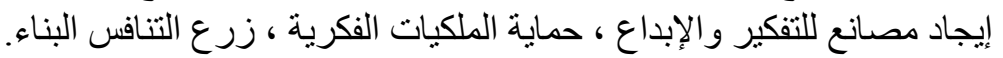

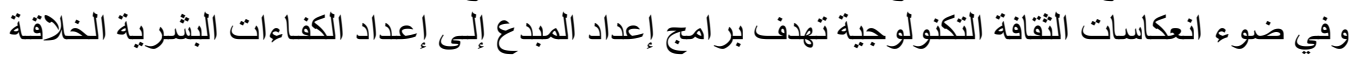

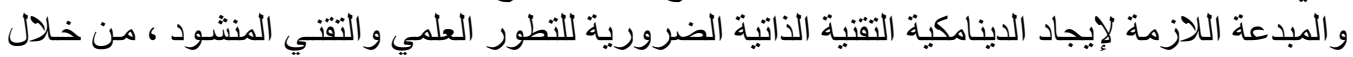
تحقيق مجمو عة من الأهداف منها مايلي:1- تكوين مهار ات عامة في التفكير و التخطيط و التكيف المعرفي و النفي النفسي و التعامل مع المتغيرات.

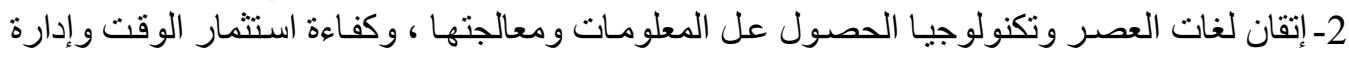

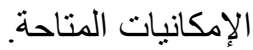
3- الانتقال من التعليم القائم إلى التعليم المستمر ، ومن تلقي المعلومات إلى معالجتها ومن المعارف إلى الـى

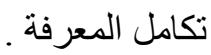

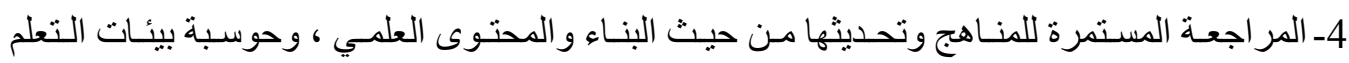
و التدريب على استخدام البرمجيات و الوسائط المتعددة وطرق البحث عن المعلومات.

2/6/4 - أوجه القصور القائمة في تدريس علوم التصميم :

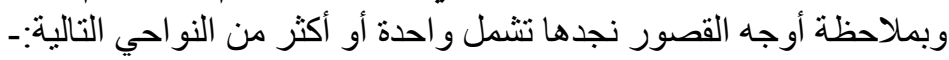

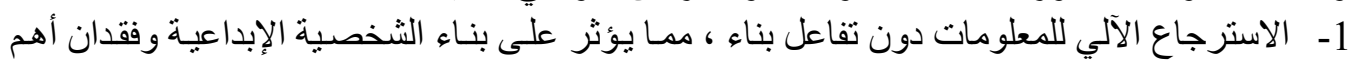
مقوماتها. 2- الرفض غير المبرر للانفتاح الواعي على مختلف الاتجاهات و المدارس التصميمية الحديثة وفرض

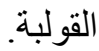

3- عدم تو افر المرونة الكافية للمناهج وطرق التدريب التدريس لمو اكبة التطور ات المتلاحقة.

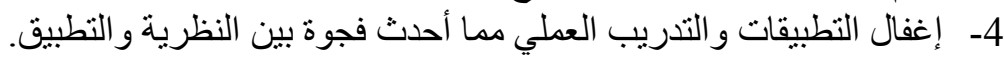

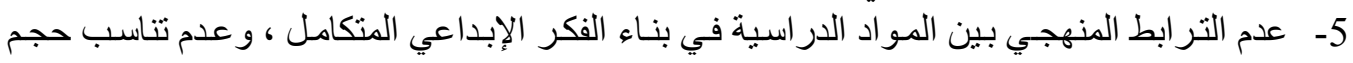

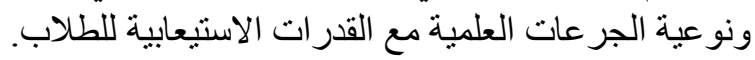

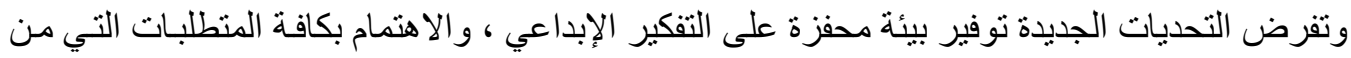

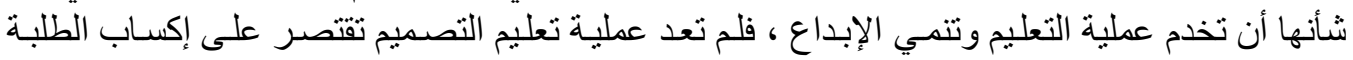

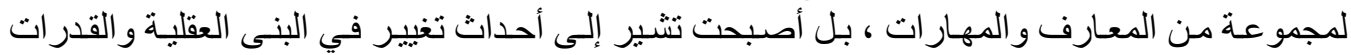




\section{3/6/4- أهم خصائص التعليم الإبداعي:}

1- التعليم الإبداعي هو الذي يستجيب لأنماط التغيير الخاصة بالطالب و التي ترتبط بالخصـائص العقلية و والإنمائية.

2- هو الذي يجعل من الفرد باحثا عن الأسباب و العلاقات أكثر منه باحثا عن النتائج.

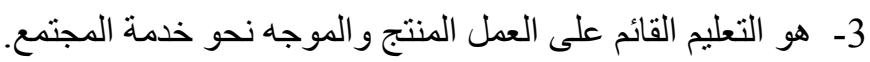
4- هو الذي يربط النظرية والجو انب التطبيقية العملية. 5- هو الذي يتضمن معارف ومهار ات و اتجاهات قابلة للبقاء و الاستمر ار، و هنالك مجمو عة من العمليات

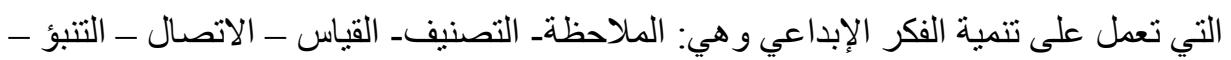

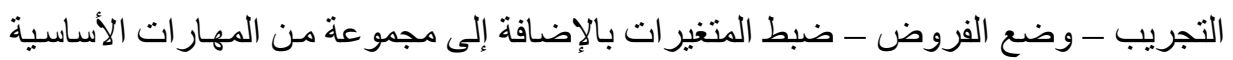

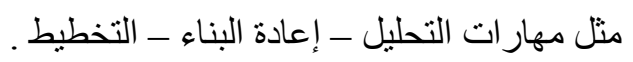
7/4 - نتائج البحث: على ضو ء محاور الدر استة يمكن استخلاص بعض النتائج ذات الصلة بمستقبل التصميم المعماري على مستوى الممارسة و التعليم كما يلي:

1- إن التوجه المستقبلي ومحاولة صنع المستقبل أصبح من سمات العصر الحديث، ومن أهم توجهات المستقبل في خطط التحديث مايلي:

• التحول من المجتمع الصناعي إلى مجتمع المعلوماتية و الذكاء الإصطناعي.

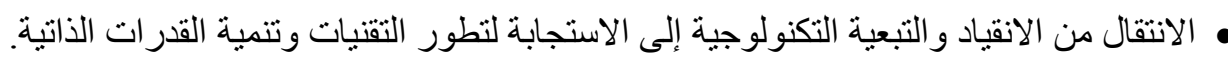

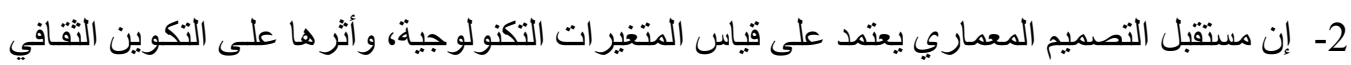
و الاجتماعي و الاقتصادي للمجتمع.

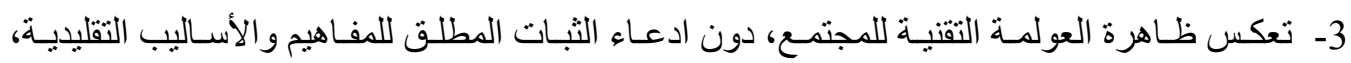

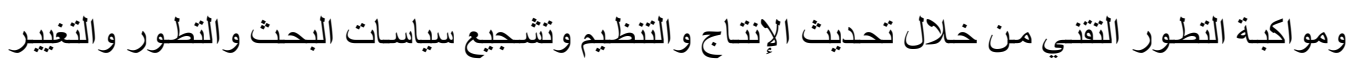
المخططو وتوفير المناخ الإبداعي. 4- إن منطق العلاقة بين التصميم و التكنولوجيا يكمن في التكامل و التوافق وتبادلية التأثثر ، وتمثل الثورة

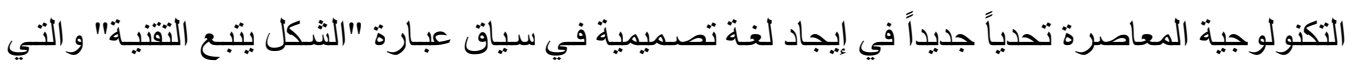

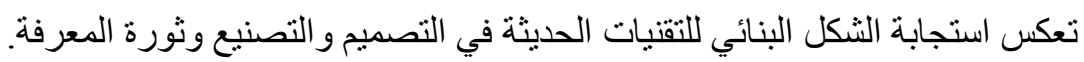

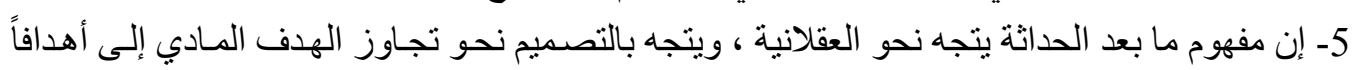
أكثر عمقاً وأصاله ، فتصبح العمارة لغة لهو لهوية.

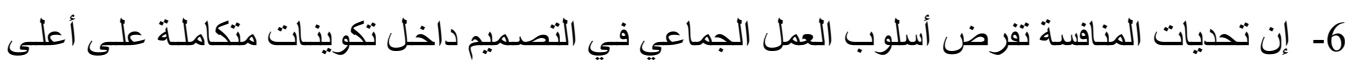
مستوى من التنظيم و الأداء و الإنتاج.

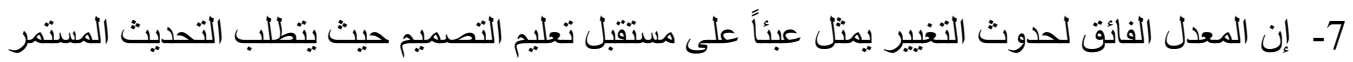

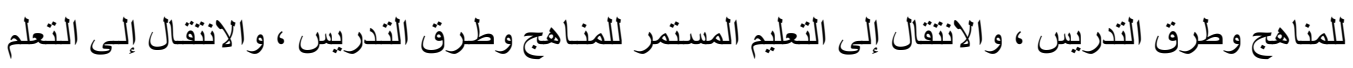

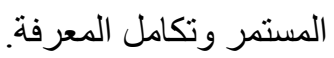


8- يـرتبط الإبـداع بالمنـاخ الثقافي للمجتمـع و الظـروف الموضـوعية لاسـتنباته ونمـوه ، حيـث تفرض التحديات التقنية نوفير بيئة محفزة على التفكير الإبداعي.

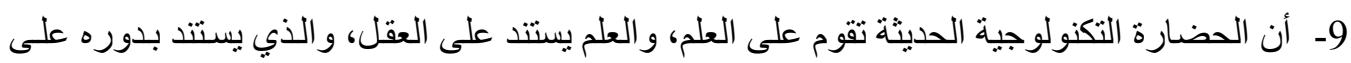
الإنسان وبالعلم يتحقق له المزيد من الكمال و الانضباط على المستوى الإنساني.

\section{المراجع والأبحاث المنشورة}

1- عفيف البهنسي - من الحداثـة إلى مـا بعد الحداثة في الفن - دار الكتاب العربي - دمشق -

.1997

2- محمد حمد الطيطي - تنمية قدر ات الفكر الإبداعي - دار المسيرة للنشر التوزيع - عمـان -

2001

3- نبيل علي - العرب و عصر المعلومات _ كتاب عالم المعرفة (84) - الكويت - 1997م.

4- Brad T.wells office furniture industry kicks high tech mode - American city - Business journal - Inc - August 97.

5-Colin Davies - High tech Architecture -Thames \& Hudson Ltd - London -88 .

6- Kazys Varnelis - Post modern permutations - MIT Architecture - 2000.

7- Kushal Dave - The arts go high tech - The yale herald Inc -usa-1998. 